\title{
EESTLASTE OMA AJALOOTEADUS
}

\author{
ANTI SELART
}

$\mathrm{K}$

as eesti rahvuslik ajalooteadus on lihtsalt eestlase kirjutatud ajalooteadus? Või peaks rahvuslik ajalooteadus kuidagi nimme ajama eesti rahvuslikku asja? Ega me muidugi ei tea õieti, mis see rahvuslik asi on, alates tõigast, et „rahvuslikuks” tõlgitakse eesti keelde väga sageli ingliskeelset sõna national, mis tähendab ju mõnikord hoopis „riiklikku”. Kui riik finantseerib ajaloolaste tegevust, siis kas tal on õigus või põhjus ette kirjutada, missuguseid eesmärke (võib-olla ka teadusväliseid) ajaloo uurimine ja ajaloost kirjutamine peab täitma? Kuidas üldse avalduvad ajalookirjutuses rahvuslikud huvid? Kas Eesti ajalookirjutuse teaduslikkuse või rahvuslikkuse määr sõltub sellest, kas autor on näiteks eestlane, venelane, sakslane või inglane, kas ta elab Eestis või välismaal?

Pool aastakümmet tagasi, kui Eesti ajaloo üldkäsitluse keskaja-köitest (Eesti ajalugu 2012) sai autorite jaoks ootamatult avaliku väitluse objekt, kõlasid need küsimused korduvalt. Ajakirjandus, oma ärihuvis vaidlusi õhutades, muidugi lihtsustas küsimuseasetusi. Kogu see lugu näitas, et erialainimeste arusaamad teadustöö sihtidest võivad osutuda isegi huvilise ja koolitatud lugejaskonna jaoks raskesti mõistetavaks. Näiteks ilmnes, et suure osa meie lugeva publiku meelest jaguneb ajalugu õigeks ja omaks ning võõraks ja (võimalik, et) valeks.

Elukutselise ajaloolase seisukohast on niisugust jaotust raske omaks võtta. Pigem tahaks ajalooteaduse jagada professionaalseks ja ebapädevaks. Ajalugu, nagu iga teinegi teadus, peab olema objektiivne: kui uurija tahab, et teda tema rollis tunnistataks, peab ta lähtuma aktsepteeritud erialareeglitest (Tamm 2014). Iseennast ja oma maailma ta oma töödest nagunii kõrvaldada ei saa. Juba uurimisküsimuse valik ütleb üht-teist uurija enese kohta. Erialareeglite hulka kuulub ka allikakriitika, mille puhul tuleb muuhulgas arvestada inimeste loodud allikate paratamatu subjektiivsusega (Tarvel 2013b [2005]). Niisiis on objektiivne ajalooteadus selline, mis lubab erinevaid tõlgendusi ja vaatenurki, kui need tuginevad mineviku kohta kõneka teabega ümberkäimise tunnustatud viisidele, ja on avatud võimalusele saada ümber lükatud lisanduva teabe või parema seletuse poolt. Ning kahtlemata avaldub selles kõiges vähemal või rohkemal määral ka päevakajalisus (vt Lang 2014), nii ühiskonna ootuste määratud uurimisteemade kui ka mõnikord lihtsalt pelka sõnamängu suubuva akadeemilise moe vormis (Kala 2011).

Muidugi pole tähtsuseta ka „metahistoorilised žestid”, kui kasutada Jaan Unduski väljendit (2000), ehk see, kuidas sisuliselt ühest ja samast asjast saab rääkida täiesti erineva tundetooni ja väärtushinnangutega. Kas linnuse piiramist tuleks nimetada selle kaitsmiseks või langemiseks? Linnust kaitsti ja see langes, aga üks sõna rõhutab selle kaitsjate vaprust, teine vallutaja võitu. Ülestõusnutega oleme me kaasas, aga mässajad jäävad võõraks. Või kui tuua 
konkreetsem näide: kas piiratud mahuga kirjutises, nagu õpik või entsüklopeediaartikkel, tuleks tõsta esile 1210. aasta Ümera lahingut või 1217. aasta Madisepäeva lahingut? Esimese Ugandi ja Sakala eestlased võitsid, teine oli kahtlemata palju suurem lahing.

Isiklik kogemus, elav traditsioon ja õpitu ning omandatu kujundab selle, mida minevikust teatakse ja mida oluliseks peetakse. Eesti poliitiliselt vaheldusrikas ajalugu on aegade jooksul toitnud ettekujutust, et meie pärand jaguneb omaks ja võõraks. Ilmselt tõesti saab vähemalt isikliku kogemuse põhjal esile tuua näiteks rajatisi, mis on ühemõtteliselt seotud mälestustega kogetud vägivallast ja meenutavad halba. Arusaadavalt on siin oluline ajaline distants. Veel ilmasõdade vahel polnud Eesti vanema kunsti omaksvõtmine eestlaste poolt sugugi vaidlustest vaba (Jõekalda 2014). Ajakirjanik Tõnis Braks protestis 1937. aastal keskaegsete linnusevaremete konserveerimise ja restaureerimise vastu: „Me ei liialda palju, kui ütleme, et iga kivi neis orjaisandate losside süngeis seinus on niisutatud meie esivanemate higi ja verega. [---] kui võõras külastab Tartu või Viljandi lossimägesid, siis on ta esimeseks huviobjektiks loomulikult varemed. [---] Võõraste silmis pole meil, eestlasil, midagi." (T. B. 1937) Tänaseks on „saksa” varemed omaks võetud. Kersti Markus toonitas kord ühes ettekandes: keskaegse kunstipärandi omakskuulutamist ilmestab ju kõige paremini Tallinna ordulinnuse torn Pikk Hermann, mis tänapäeval enesestmõistetavalt meie lippu kannab. Tõsi, saab öelda ja on öeldud, et eestlaste käed on need kivid müüri ladunud. Hea kunsti omanik on ehk sellepärast hea olla, et sel on lisaks esteetilisele ja ajaloolisele ka aineline väärtus. Kuid põhiline on, et eesti-saksa konflikt, mis vähemalt kuni 1939. aastani oli aktuaalne, on oma poliitilise pinge kaotanud ja sakslased ei taotle samuti enam minevikupärandi rahvuslikku jagamist.

Kultuuriliselt on tänapäeva eestlased ju nii Lembitu ehk muinaseestlaste kui ka Alberti ehk vallutajate järeltulijad. Veel aga on meie mõtteilma verminud ettekujutus - tegelikult tõestamata hüpotees -, et lisaks kuulumisele sõjalistesse ja poliitilistesse vastasleeridesse lahutas nimetatud mehi ka ületamatu lõhe kahe maailma vahel. Eluterve rahvusliku eneseteadvuse jaoks on oluline heameel minevikus omal maal toimunu rikkusest ja mitmekülgsusest ning arusaam, et tänast olemist on kord rohkemal, kord vähemal määral kujundanud kõik minevikusündmused, ka need, mille kohta mingil põhjusel tahaks, et need poleks aset leidnud. Ja ettekujutused minevikust omakorda mängivad kaasa inimeste uute tegude vermimisel (Tamm 2012a [1998]). Tõnis Lukase sõnul: Jüriöö ülestõusu ,tähendus Eesti ajaloos ei muutuks vist isegi siis, kui keegi jõuaks järeldusele, et ülestõusu [---] ei toimunudki” sellisel viisil, nagu seda tavaliselt ette kujutatakse (Lukas 1993: 691).

Eesti ajaloo puhul on vastandatud - kasutades saksa keelest laenatud termineid Landesgeschichte ja Volksgeschichte - maa ajalugu ja rahva ajalugu (Vestlus... 2000; vrd nt Kaljundi, Plath 2017). Esimene räägib maa kui terviku ajaloost, teine kas eestlaste või (balti)sakslaste ajaloost Eestis (vt bibliograafiat Rosenberg 2014). Kui väitlus nende lähenemiste üle sõdadevahelisel ajal päevakorral oli, ilmnes, et baltisaksa autorite meelest oligi keskaegse Liivimaa sõdade, ordumeistrite ja piiskoppide ajalugu poliitilise ajaloona kogu maa ajalugu, samal ajal kui eestlaste arvates oli see vaid sakslaste endi ajalugu, mis jättis eestlased kõrvalisse rolli. Õige eestlane oli aga esmajoones talupoeg, 
niisiis tuli rahvusliku ajaloona uurida agraar- ja talurahva ajalugu. Samal ajal avastas tegelikult just baltisakslane Paul Johansen keskaegse linnaeestlase. Sellest hoolimata on eestlaste hilisem linnastumine võrreldes Lääne- ja KeskEuroopa rahvastega tinginud tänini elava ettekujutuse, nagu oleks õige ja päris eestlane alati olnud talupoeg, linn ja mõis aga olnud eestlastele ajalooliselt võõrad nii rahva kui ka vaimu poolest. Teatavasti juba linnainimesest insener Ludvig Sander teadis, et kõik meie omapärasus on laudas ja aganikus.

Ilmasõdade vahel kirjutasid Eestis ka teadlased ajalooteaduse rahvuspedagoogilisest ülesandest. Hans Kruusi 1930. aastal sõnastatud üks kategoorilistest imperatiividest Eesti ajaloo uurimisele kõlas: „Kodumaa ajalugu peab olema rahvale kasvatajaks” (Kruus 2005 [1930]: 127). Aga samas siiski: „[---] seda rakendame oma rahvuspedagoogika teenistusse õieti suunatud uurimistööga, mis toimub moodsa ajalooteaduse nõuete järgi, maha kiskudes sihilikult tekitatud väärarvamusi ja teisest küljest põhjendamatuid illusioone ja idealiseeringuid, käsitledes oma ainet teaduslikult kainelt, samal ajal aga soojuse ja armastusega oma väikese heroilise, kuid sajandite kestel kurva saatuse osaliseks olnud rahva vastu" (Kruus 2005 [1930]: 132-133). O. Liiv leidis tollal, et romantilis-heroilised liialdused tulevad ette igal maal ja kuigi see joon „võib [---] kanda ebaõigeid tulemusi”, siis ometi „on ta ajuti nähtavasti koguni vajalik. Meie näeme sellist käsitlusvormi praegu Saksamaal, sealsel praegusel uurijatepõlvel ja loeme seda ka loomulikuks, pidades, nagu Saksamaal, nii ka Soomes, Lätis, Poolas ja mujal, rahvuslikku ajalookäsitlust praeguseks üheks üldisemaks lähenemisvormiks ajaloouurimisel. Muidugi ei kiida meie liialdusi heaks, kuid nende tähtsus tulevikus kaob paratamatult kui väärtuseta element." (Liiv 1938: 302) Ühesõnaga, ka rahvusliku võitluslikkuse vajalikkust rõhutades seisis siiski teaduslik pädevus esimesel kohal.

Ajalooteadusel endal on ajalugu. Siin, nagu igas teaduses, on olnud meetodeid ja tõlgendusi, mis on jäetud kõrvale, sest nad on osutunud valeks. Arusaam, et eksisteerib päritav rahvuse vaim, ehk ettekujutus natsioonide ajaloolisest püsivusest vastas 1930. aastate rahvusvahelisele teaduslikule standardile. Seega pole põhjust tollaseid Eesti autoreid väheses teaduslikkuses süüdistada. See, mis on komplitseerinud eestlaste suhtumist oma ajaloosse ja mille mõju end arvatavasti siiani tunda annab, on Nõukogude okupatsioon, mis esiteks isoleeris Eesti ajalooteaduse üsna tõhusalt muu maailma arengutest, teiseks sundis peale kas otsese riikliku ideoloogia teenimise või vähemalt spetsiifilise sõnavara (Undusk 2003) ja kolmandaks piiras oluliselt Eesti ajaloo teadusliku uurimise ainelisi võimalusi. Mäletatavasti ei ilmunud Eesti NSV-s ühtegi ajaloo ajakirja. Kokkuvõttes kujunes 1980. aastate lõpuks avalik arusaam, et vähemalt vanema ajaloo osas tuleb tagasi minna sõjaeelse ajalookirjutuse juurde, just seal peitub muutumatu tõde. Olgu mainitud, et teatud ajalise nihkega on mõnevõrra sarnane olnud areng Venemaal, kus nõukogude ajal juurdus laialdaselt arusaam ametlikust ajaloost, ühest ja muutumatust ajaloolisest tõest. 1980. aastate lõpul hakati massiliselt taastrükkima tsaariaegseid ajalooraamatuid. Uute ja erinevate käsitluste tulvale alates 1990. aastatest vastati aga üha sagedamini nõudega naasta vana, selle ühe ja õige juurde. Eriti hästi on see jälgitav suhtumises endiste alistatud rahvaste, näiteks ukraina, ajaloolaste töödesse. Hiljemalt nõukogudeaegset standardit peetakse teaduslikuks tõeks, sellest hälbimist nähakse ainult venevaenuliku 
vassimisena. Oma rahvale iga hinnaga kuulsusrikka mineviku ehitamine on tõepoolest endises Nõukogude Liidus väga laialt levinud, aga nimetatud eelhäälestus heidab sageli a priori kõrvale ka teaduslikult pädeva ajalookirjutuse - taipamata või tahtmata taibata, et see Vene nii-öelda standardajalugu on loodud ajal, kui iga hinna eest oma rahvale kuulsusrikka mineviku ehitamine oli teaduses veel täiesti aktsepteeritav.

Kui väitlus rahvusliku ajaloo üle jõuab ajakirjandusse, siis paistab, et teadlased ja laiem publik räägivad tegelikult eri asjadest. Eestis on XIII sajandi sündmuste käsitlemist ristisõdade ajaloo raames nimetatud n-ö saksa vaatepunkti ülevõtmiseks. See on kindlasti vale. Saksa ja eesti traditsioonilised käsitlused on pigem olnud sisult sarnased ja erinenud esmajoones just metahistooriliste žestide poolest. Mõlemas on esiplaanil vallutajatele omistatud (ajakohatut sõnavara kasutades) majanduslikud ja geopoliitilised, eriti 1930. aastate vaates ka rahvuspoliitilised huvid. Sellele arusaamale vastandub 1970. aastatel angloameerika ajalookirjutuses alguse saanud nn uus ristisõdade käsitlus, mis toob esile, et pelgalt aineliste huvidega ei saa ristisõtta läinute tegevust seletada ja et ristisõdade ajalugu on nii aja kui ka ruumi poolest hoopis laiem kui ainult võitlused Püha Maa pärast aastatel 1096-1291 (Kaljundi 2007). Võrdluseks, Soome ajaloos on ristiretkiaika 'ristiretkeaeg' juba ammu juurdunud periodiseering ja seda pole peetud võõrapäraseks. Eesti Muistse vabadusvõitluse termini (Selart 2003) lähtekohaks on 1930. aastate teaduslik ettekujutus poliitilise iseolemise kaitsele asunud demokraatlik-vabariiklikust Muinas-Eestist, mis oleks välise sekkumiseta jõudnud oma riikluse kujunemiseni. Kuid tänaseks on teadlaste pilt muinasühiskonnast oluliselt teisenenud ja Muistse vabadusvõitluse termin muutunud sisuliselt anakronistlikuks (vrd siiski Lang 2014: 56), sest siin on silmas peetud poliitilist vabadust moodsas mõttes, mitte keskaja ühiskonna arusaama vabadustest kui isikute ja rühmade ühiskonnas ebavõrdselt jagunevate eesõiguste ja kohustuste süsteemist.

Magnus Ilmjärve raamatu „Hääletu alistumine” (2010 [2004]) ümber käinud vaidlustes paistis avalikkusele silma küsimus, kas Konstantin Päts oli Eesti riigi reetur. Erialaselt oli väitluse sisu hoopis selles, kas autor on oma allikatega alati ausalt ja korrektselt ümber käinud (vt Valge 2012). Veel ühe ilmeka ja omal moel sarnase juhtumi leiab taas naabrite juurest. Aastal 2011 kaitses Vladimir Medinski (Venemaa kultuuriminister aastast 2012) Venemaa Riiklikus Sotsiaalülikoolis ajaloodoktori kraadi tööga, mis paljastas Venemaast kirjutanud varauusaegsete välisautorite valelikkuse. Nagu on tõdenud hilisemad retsensendid, oli töö meetod kuulutada Venemaa jaoks tänapäeva vaatepunktist negatiivne info ekslikuks ja lugeda „head” teated õigeks. Mõned Venemaa ajaloolased on nõudnud tema kraadi tühistamist. Keerukate bürokraatlike protseduuridega jõuti 2017. aasta oktoobris kõrgema atestatsioonikomisjoni presiidiumi otsuseni jätta kraadi andmine jõusse, hoolimata sama komisjoni ajalooteaduste ekspertnõukogu vastupidisest seisukohast ja tõdemusest, et töö autoril puuduvad erialased põhioskused. Kuid avalik diskussioon on käinud hoopis muu ümber: minister on alati väitnud, et tema meetodiks olevat Venemaa huvide kaitsmine, ja kui keegi väidab, et see polevat Vene ajaloolase esmaülesanne ja teaduslik metoodika, siis järelikult kaitseb too mõne teise (loe: Vene-vaenuliku) riigi huve. See seisukoht on leidnud küllalt toetajaid. Ka Eestis on arvatud, et „ajalookäsitlus on tööriist, mida kasuta- 
takse mingite poliitiliste eesmärkide nimel. [---] ei ole õiget ega valet ajalugu, vaid on kasulik ja mittekasulik ajalugu." (Hvostov jt 2001: 47 [Hvostov])

Niisiis on ajalugu ikka ja jälle kasutatud poliitilise argumendina. Mingil viisil ta seda paratamatult ka on. Kui uuema ajaloo uurimine võib anda riiklikes või isiklikes vaidlustes juriidilisi argumente, siis vanemast ajaloost leitakse moraalseid argumente. Aga kui kauge ajalugu üldse on veel argumendina kasutatav (vrd Tarvel 2013a [2000])? Eesti 1919. aasta maareform lähtus poliitilisest ja sotsiaalsest vajadusest, aga siin põrkusid suurmaaomanike legaalse eraomandi õiguslikud ja eestlastele paljude sajandite eest osaks saanud ülekohtu ajaloolised argumendid. Kumb on tugevam põhjend, kas notariaalne ostu-müügileping või keskaegse krooniku jutustus verisest lahingust? Kas eesti talupoegade allasurutud seisund XIX sajandil üldse on põhjuslikus seoses XIII sajandi vallutusega?

Kaugemast minevikust pärit argumentide kasutamine riikide ametlikus poliitikas on tänapäeval - vähemalt Euroopas - siiski pigem kurioosum. Kuid ajaloolised argumendid võivad huvirühmade konkurentsis kõlada ka siseriiklikult. Eesti uuspaganlus (nn maausk) lähtub suuresti 1930.-1950. aastatel Oskar Looritsa sõnastatud mõtetest (Selart 2014). Sel ajal oli idee rahvaste geneetiliselt päritavast vaimust teaduses aktsepteeritav ja rahvakultuuri mittekristlikes (mida mõõdeti uusaja vägagi luterliku mõõdupuu järgi) elementides nähti keskajaeelset paganausku. Tänapäeva teaduse seisukohalt on mõlemad arvamused valed (Jonuks 2012), järelikult ka Looritsa muinaseesti religiooni konstruktsioonid.

Mitmed rahvuslikuks peetud eripärad ajaloos - nagu eriti „Eesti” ja „Euroopa” vahele ajaloolise eraldusjoone tõmbamine - tuginevad omapäraotsinguile ja tulenevad suuresti Euroopa ajaloo vähesest tundmisest. Kui XV sajandil seisis saksa talupoja usk tõepoolest kiriklikule ideaalile lähemal kui eesti talupoja oma, siis ühel oli seljataga kus ligi tuhat, kus oma pool tuhat aastat kateheesi, teisel vaid paarisaja aasta jagu. Nii luterlik kui ka saksavastane traditsioon on Eesti ajaloost tihti nimme otsinud võõristust talupoja ja katoliku kiriku vahel. Tegelikult polnud ka Lääne-Euroopas lihtrahva religioonikäsitlus sugugi normipärane. Euroopa on alati olnud palju heterogeensem, kui loetud õpikud ja külastatud turismilinnad seda arvata lasevad. Võrreldes Eestit ja Lääne-Euroopat nende ajaloolises arengus on sageli tegu pigem ajaliste nihetega, mitte olemuslike erinevustega. Kuid küsimus Eesti ajaloo täisväärtuslikkusest kerkib ikkagi regulaarselt üles. „Üks mitte-eurooplase-kompleksi moodsamaid variante näib olevat idaeurooplaseks-olemise-kompleks" (Jansen 1997: 38).

Teaduslik pilt, ükspuha millest, on muutlik - muidu poleks ju tegu teadusega, mis peab esitama uusi küsimusi ja otsima uusi, senistega võrreldes paremaid vastuseid. Teaduslik pilt võib varem või hiljem lausa valeks osutuda. Käib teaduse iseloomu juurde, et oletuste tõendamine on keerulisem kui nende kummutamine. See kõik kehtib ka teadusliku minevikupildi kohta. Isegi vanema ajaloo valdkonnas, kus on vähe lootust, et ilmuksid päevavalgele seni täiesti tundmatud kirjalikud allikad, muudavad uued küsimuseasetused ja uurimisviisid ettekujutust selle kohta, mis kunagi oli.

Seetõttu ei saagi rahvuslust või rahvuse huvisid riputada ühe konkreetse minevikupildi külge. See on ohtlik rahvusele endale (Hvostov jt 2001: 47, 49 
[Laar]). Teaduslikult iganenu külge klammerdumine võib osutuda paremal juhul naeruväärseks, halvemal juhul anda põhjust vägivallaks. Lubatagu siinkohal veel viimane võrdlus Venemaaga: kunagi ka teadlaste poolt propageeritud kujutlust, et kõik head asjad maailmas on leiutatud venelaste poolt, on juba aastakümneid esmajoones venelased ise välja naernud tuntud naljaga Nõukogude Liidust (või Venemaast) kui elevantide kodumaast. Aga Teise maailmasõja „ametliku” käsitluse murendamise vastu on Vene riik kasutanud surveabinõusid ja ähvardusi. Ilmselt on Eesti kui väikese maa voorus, et meile jääb siinkohal vaid naeruväärsuse võimalus. Oleks väga hea jätta naerualuseks saamata. „Minevikuromantika on hädaaegade ilu [---] Noorele rahvale sobib pühapäevikski pigemini juba tulevikuromantikat [---]" (Annist 2011 [1935]: 129).

Kõik erialateadmised ei olegi väljaspool teadust inimeste elus vajalikud. Toimetulekuks kultuuris on lugu Romulusest ja Remusest olulisem kui arheoloogide viimased oletused Rooma linna sünni kohta. Samal ajal on tähtis, et ühiskonnas mõistetaks teaduse ja pärimuse omavahelist keerukat suhet. Pärimus ja teadus on erinevad. Kui keegi nimetab tänapäeva roomlasi Romuluse järglasiks, on see ilus kõnekujund. Romuluse lugu on tõsiselt võetav uurimisteema. Aga kui väide „21. aprillil aastal $753 \mathrm{eKr}$ asutas Romulus Rooma linna” oli paarisaja aasta eest ka tollases teaduslikus ajalookäsituses igati omal kohal, siis tänapäeval oleks selline kindel väide samas funktsioonis paremal juhul pentsik. Nii elavad rahvuslikud lood ja teaduslikud lood omaette elu: mitte isoleeritult, kuid siiski iseseisvalt. Kõik on korras, kui nende vahel osatakse vahet teha.

Eesti ajalooteaduse ees on kaks raskesti ületatavat takistust: geograafia ja demograafia. Hoolimata käibetõest, et meie maa on ikka seisnud ajaloo tõmbetuultes, on ta alati olnud kaugel suurte ja rahvarohkete maade keskusist. See tähendab, et loomulikus turuolukorras on Eesti ja eestlaste ajaloo uurijaid paratamatult vähe. Ei aita palju isegi asjaolu, et Eesti on ajaloos kuulunud suuremate maade külge. Kirjastused ja ajakirjad, kellele on oluline müüdud tiraaž ja loendatud klikid, eelistavad arvukama lugejaskonnaga teemasid. Kardetavasti liiga väikese lugejate arvuga töö avaldamist ei hakka mõni rahvusvaheline suurkirjastus arusaadavatel põhjustel tõsiselt kaalumagi, olgu selle teaduslik kvaliteet kui tahes kõrge. Rohkem erinevate autorite publikatsioone, st rohkem väitlust tähendab aga lõpptulemusena ka kõrgemat kvaliteeti. Ühe sõnastuse järgi on teadusliku ajaloouurimise eeldusteks välise sunni puudumine ning teadlaskonna piisav heterogeensus ja suurus (Tamm 2014: 131). Et meil oleks piisavalt teaduslik ajalookirjutus, peab meil olema piisavalt palju elukutselisi, erinevates institutsioonides töötavaid ja samu või sarnaseid uurimisülesandeid erineval viisil lahendavaid uurijaid.

Väikesel maal on küllaldast kogust teadust koha peal raske luua, see nõuab pikaajalist tööd inimeste koolitamisel ja institutsioonide ülesehitamisel. Mõned maad ja rahvad on lisaks teadlikult ja edukalt investeerinud oma ajaloo rahvusvahelisse uurimisse, et geograafia või demograafia seatud piiridest üle saada. See on õige otsus, aga tulemuslikkuseni jõudmine nõuab ikkagi palju aega, veel rohkem raha ja kannatust. Selleks et meist rääkiv ajalugu oleks suur ja atraktiivne, peavad seda uurima ka need, kel isiklikult Eesti või eestlastega pistmist polegi. Eesti ajalugu, nagu üldse ajalugu, ei kuulu 
kellelegi (Tamm 2012b [2009]). Meie rahvuslik huvi (vt Taagepera 2008) peab olema, et seda uuritaks võimalikult vabalt, võimalikult palju ja võimalikult hästi.

Uurimust ei ole toetanud ükski institutsionaalne uurimisprojekt. Kuna Tartu Ülikooli raamatukogu fondid on maja remondi tõttu jätkuvalt põhilises osas ligipääsmatud, ei vasta resultaat mitte igas punktis soovitule.

\section{Kirjandus}

Ann is t, August 2011 [1935]. Muinsusromantika osast Eesti arengus. - A. Annist, Noorusmaa. (Eesti mõttelugu 98.) Koost Hando Runnel. Tartu: Ilmamaa, lk $111-130$.

Eesti ajalugu 2012 = Tiina Kala, Linda Kaljundi, Juhan Kreem, Ivar Leimus, Kersti Markus, Anu Mänd, Inna Põltsam-Jürjo, Erki Russow, Anti Selart, Marek Tamm, Heiki Valk. Eesti ajalugu II. Eesti keskaeg. Koost, toim A. Selart. Tartu: Tartu Ülikool.

Hvostov, Andrei, Laar, Mart, Tiido, Harri 2001. Mõttevahetus. Ajalooline müüt rahvuslikus identiteedis. - Eesti identiteet ja iseseisvus. Koost A. Bertricau. Tallinn: Avita, lk 44-54.

Il mjärv, Magnus 2010 [2004]. Hääletu alistumine. Eesti, Läti ja Leedu välispoliitilise orientatsiooni kujunemine ja iseseisvuse kaotus. 1920. aastate keskpaigast anneksioonini. Tallinn: Argo.

Jansen, Ea 1997. Hajamõtteid Eesti ajaloo uurimisest. - Kleio. Ajaloo ajakiri, nr 1 , lk 35-41.

Jon uks, Tõnno 2012. Rahvuslus ja muinasusund: religioon eestlase loojana. Ajalooline Ajakiri, nr 3-4, lk 269-285.

Jõekalda, Kristina 2014. „Võõra” pärandiga leppimine ja lepitamine. 1920.1930. aastate debatid ajaloolise arhitektuuri väärtuse ja kaitse üle. - Maastik ja mälu. Pärandiloome arengujooni Eestis. Koost Linda Kaljundi, Helen SooväliSepping. Tallinn: TLÜ Kirjastus, lk 182-245.

Kala, Tiina 2011. Eesti vanem ja uuem medievistika. - Kõnetav kultuur. Koost Rein Veidemann, Õnne Kepp. Tallinn: Eesti Keele Sihtasutus, lk 163-178.

Ka lj u n di, Linda 2007. Püha sõja otsinguil: ristisõdade uuemast historiograafiast Euroopas ja Läänemeremaades. - Ajalooline Ajakiri, nr 2, lk 193-223.

Kaljundi, Linda, Plath, Ulrike 2017. Eesti ajalookirjutus põimitud perspektiivist. - Tuna. Ajalookultuuri ajakiri, nr 1, lk 2-6.

Kruus, Hans 2005 [1930]. Ärkamisaja pärandus Eesti ajaloo uurimisele. H. Kruus, Eesti küsimus. (Eesti mõttelugu 62.) Koost Toomas Karjahärm, Hando Runnel. Tartu: Ilmamaa, lk 122-133.

Lang, Valter 2014. Muinasmaastike avastamine. Essee mineviku tõlgendamisest ja ühiskondlikust tellimusest. - Maastik ja mälu. Pärandiloome arengujooni Eestis. Koost Linda Kaljundi, Helen Sooväli-Sepping. Tallinn: TLÜ Kirjastus, lk 36-78.

Liiv, O[tto] 1938. Eesti ajaloouurimise sihist ja sisust. - Akadeemia, nr 5, lk 299-303.

Luka s, Tõnis 1993. Jüriöö võimalused. - Akadeemia, nr 4, lk 691-698. 
Rosenberg, Tiit 2014. Eesti ajalugu - kas rahvusajalugu, maa-ajalugu või regionaalajalugu? - Rahvusvahelised rahvusteadused. Artiklikogumik rahvusülikooli 95. juubeliks. Toim Tiit Hennoste. Tartu: Tartu Ülikooli Kirjastus, lk 19-39.

Selart, Anti 2003. Muistne vabadusvõitlus. - Vikerkaar, nr 10-11, lk 108-120.

S el art, Anti 2014. Germanofoobist ökoprohvetiks. Oskar Loorits ja rikutud eestlased. - Vikerkaar, nr 7-8, lk 138-157.

T a a g e per a, Rein 2008. Heitlus Balti ajaloo pärast. - Akadeemia, nr 12, lk 26052623.

Ta m m, Marek 2012a [1998]. Jüriöö-tekst Eesti ajalookultuuris. - M. Tamm, Monumentaalne ajalugu. Esseid Eesti ajalookultuurist. Loomingu Raamatukogu, nr 28-30. Tallinn: Kultuurileht, lk 65-81.

Ta m m, Marek 2012b [2009]. Kellele kuulub Eesti ajalugu? - M. Tamm, Monumentaalne ajalugu. Esseid Eesti ajalookultuurist. Loomingu Raamatukogu, nr 28-30. Tallinn: Kultuurileht, lk 39-47.

T a m m, Marek 2014. Tõde, objektiivsus ja tõendus ajalookirjutuses: pragmatistlik perspektiiv. - Tuna. Ajalookultuuri ajakiri, nr 2, lk 121-134.

T a rvel, Enn 2013a [2000]. Ajaloolase analüüsist. - E. Tarvel, Ajalookimbatused. (Eesti mõttelugu 109.) Koost Marten Seppel. Tartu: Ilmamaa, lk 58-70.

Tarvel, Enn 2013b [2005]. Kas ajalugu saab kirjutada objektiivselt? - E. Tarvel, Ajalookimbatused. (Eesti mõttelugu 109.) Koost Marten Seppel. Tartu: Ilmamaa, lk 46-57.

T. B. 1937 = Tõnis Braks, Meie restaureerime. - Päevaleht 3. XI, nr 299, lk 6.

Und u sk, Jaan 2000. Ajalootõde ja metahistoorilised žestid: Eesti ajaloo mitmest moraalist. - Tuna. Ajalookultuuri ajakiri, nr 2, lk 114-130.

Undusk, Jaan 2003. Retooriline sund eesti nõukogude ajalookirjutuses. - Võim ja kultuur. Koost Arvo Krikmann, Sirje Olesk. Tartu: Eesti Kirjandusmuuseum, lk 41-68.

V alg e, Jaak 2012. London, Berliin ja Moskva ning Eesti 1934. aasta riigipööre. Tuna. Ajalookultuuri ajakiri, nr 1, lk 38-61.

Vestlus... 2000 = Vestlus Jüri Kivimäega. - Vikerkaar, nr 8-9, lk 124-136.

\section{Estonians' own historical research}

Keywords: historical writing, historical research, Estonian history

The article addresses some recent discussions on the relations between historical research and national interests in Estonia. In a general case, professional historians and the public have approached the problem differently. By the public, scholarly discussions on different scientific approaches as well as on whether this or that publication is fully based on professional standards or not have sometimes been interpreted as political debates. Well-known examples are the analysis of $13^{\text {th }}$-century Estonian history in the historical context of the Crusades, or evaluation of the activities of President Konstantin Päts in the 1930s. Due to Soviet occupation, Estonian historical research was, to a significant extent, isolated from international development and subjected to pressure from Soviet ideology. As a result, in the 1980s-1990s historical truth was often identified with the pre-Soviet 
heritage of the 1930s, a period when historical research was emphatically seen as a carrier of a national-pedagogical mission. Nevertheless, the leading historians of the time always also emphasised the importance of professional competence. However, the views of the nature and historical role of nations, which were acceptable for scholars before World War II, have ceased to be so. As a result, a considerable difference has developed, on some points of earlier Estonian history, between the popular historical vision, which still bears the influence of pre-war literature, and the scientific one, while the latter is sometimes seen as a threat to national historical memory. A solution could be brought by understanding that national identity is supported by any professional, versatile and international research of history, which together with scientific progress is indeed expected to change historical visions. Such research, however, obviously needs some extra funding, because neither the peripheral location nor the small population of Estonia stimulate, for purely economic reasons, the competitiveness of topics of Estonian history on the international market of historical research, where publishers and journals keep a close eye on circulation and number of downloads.

Anti Selart (b. 1973), PhD, University of Tartu, Institute of History and Archaeology, Professor of Medieval History, anti.selart@ut.ee 